\title{
Relaxation phenomenon in lumbar trunk muscles during lateral bending
}

\author{
D D Raftopoulos PhD \\ M C Rafko \\ $M$ Green * \\ A B Schultz PhD*
}

Department of Mechanical Engineering, The University of Toledo, Toledo, Ohio, USA.

* Department of Mechanical Engineering and Applied Mechanics, The University of Michigan, Ann Arbor, Michigan, USA.

\begin{abstract}
Summary
This paper reports myoelectric activity measurements in the lumbar trunk muscles when subjects performed tasks involving various degrees of lateral bending. Biomechanical model analyses were made to estimate the tensions in the lumbar trunk muscles required to perform those tasks. The tensions and the activity measurements were compared to see if a muscle relaxation phenomenon occurred. A relaxation phenomenon in the erector spinae muscles was observed to occur in quiet standing in a laterally-bent position of the trunk, qualitatively similar to the flexion-relaxation phenomenon reported by Schultz et al. in $1985^{13}$. However, no relaxation was observed to occur in the lateral oblique abdominal muscles in laterally-bent postures of the trunk.
\end{abstract}

\section{Relevance}

When standing in a maximum laterally-bent posture, passive mechanisms for the maintenance of equilibrium are present.

Key words: Relaxation phenomenon, Lumbar muscles, Myoelectric lateral bending

\section{Introduction}

Interest in lumbar trunk muscle contraction forces needed to perform everyday tasks arises because of the association of low back pain disorders with heavy work (Andersson et al. ' for example). Recent investigations that measured and/or predicted these forces include those of Schultz and Andersson ${ }^{2}$ and Schultz et $\mathrm{al}^{3-5}$. These studies used quantitative electromyography to validate biomechanical-model-predicted lumbar trunk muscle contraction forces required to perform physical tasks.

As early as 1911, Fick $^{6}$ suggested that the erector spinae muscles need not be active when the trunk is fully flexed. This hypothesis of a 'flexion-relaxation" phenomenon was confirmed by Allen ${ }^{7}$, Floyd and Silver ${ }^{8.9}$, Portnoy and Morris ${ }^{10}$ and Pauly ${ }^{11}$. These investigators proposed that in full trunk flexion ligamentous tissues carry the posterior tissue tensions needed to

Submitted: 8 October 1987. Returned for revision: 16 November 1987. Accepted: 13 January 1988.

Correspondence and reprint requests to: Professor AB Schultz, College of Engineering, University of Michigan, 3112 GG Brown Laboratories, Ann Arbor, MI 48109-2125, USA equilibrate upper body segments. Kippers and Parker ${ }^{12}$ quantified relations between postural configurations and myoelectric activity decreases. Schultz et al. ${ }^{13}$ quantified the tissue tensions involved in the flexion-relaxation phenomenon and showed that substantial myoelectric activity arose when exertions were made in those flexed positions.

The present study examined whether similar phenomena might arise in lateral bending of the trunk. It addressed the following questions:

1. What internal loads must lumbar trunk structures sustain in tasks involving lateral bending?

2. What levels of myoelectric activity are found in the lumbar trunk muscles in quiet standing with various degrees of trunk lateral bending?

3. Does a relaxation phenomenon occur in lateral bending of the trunk?

4. Do trunk muscle myoelectric activities increase when external forces are applied to the trunk in laterally bent configurations?

To answer these questions, measurements of myoelectric activities in the lumbar muscles were made using subjects performing tasks involving various 
degrees of lateral bending, and biomechanical model analyses were made to estimate the required tensions in the lumbar trunk tissues.

\section{Experimental methods}

Nine male volunteers aged between 21 and 25 years participated. Their heights ranged from 171 to $189 \mathrm{~cm}$, with a mean of $180 \mathrm{~cm}$, and weights ranged from 624 to $780 \mathrm{~N}$, with a mean value of $696 \mathrm{~N}$. The width and the depth of the subjects' trunks at the $\mathrm{L}_{3}$ level ranged from 27 to 31 $\mathrm{cm}$, with a mean of $28 \mathrm{~cm}$, and 25 to $20 \mathrm{~cm}$, with a mean of $18.2 \mathrm{~cm}$, respectively. All subjects were in good health and none had a history of significant back pain or injury.

Subjects were tested in an apparatus designed so that external loads could be applied, their postures could be controlled, and the mass centres of their upper body segments could be located (Figure 1). Each subject's pelvis was strapped to a support board after he assumed comfortable foot and leg positions. Subjects performed five types of tasks.

Task type 1. The subject, with his arms unsupported and at his side, bent his trunk first to the right and then to the left, in $10^{\circ}$ increments to the maximum lateral bend he could achieve.

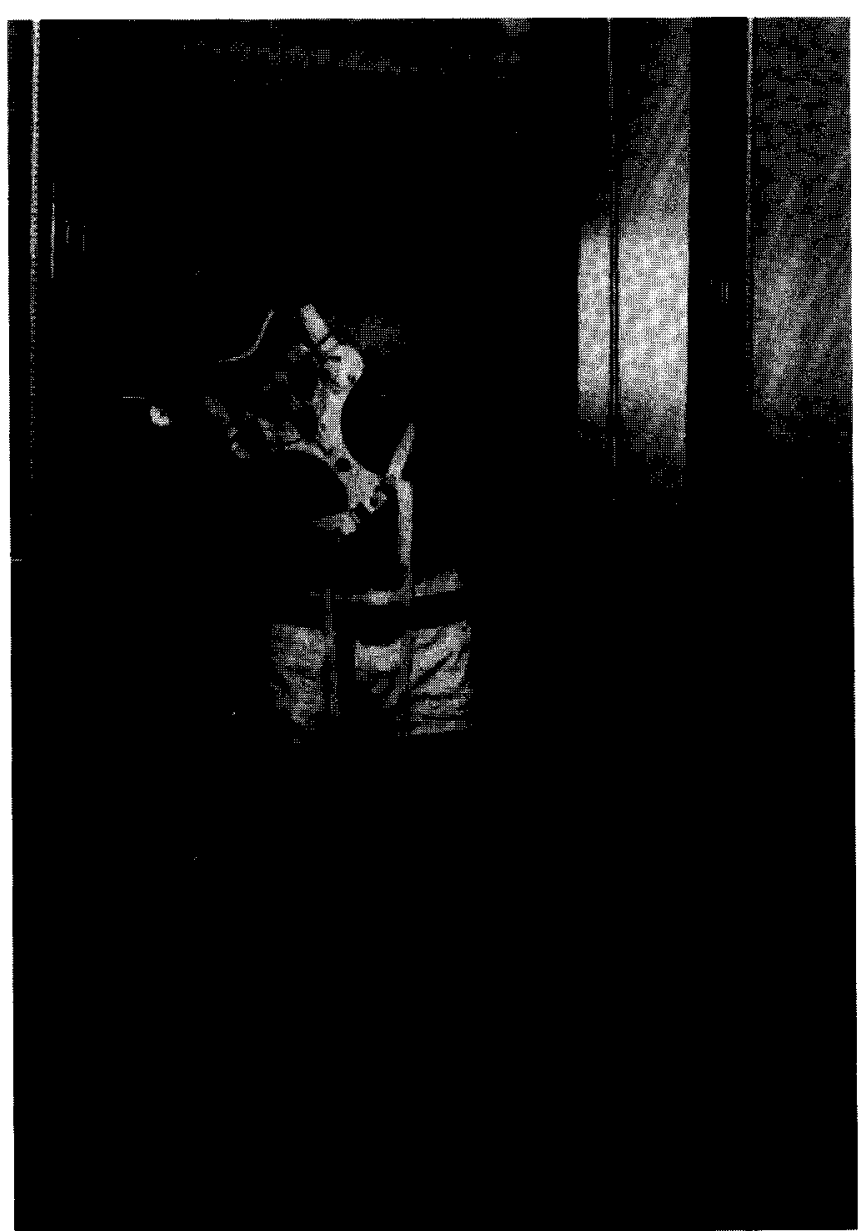

Figure 1: General view of the apparatus designed for lateral bending. The subject pulls as hard as he can on an anchored load cell.
Task type 2. The subject straightened from his maximum lateral bending posture, first from the right and then from the left, returning in increments of $10^{\circ}$ to his upright position.

Task type 3 and 4 . The subject held a $5 \mathrm{~kg}$ mass in his hand on the side to which the bending was performed, and then repeated task type 1 and 2 .

Task type 5. The subject bent, first right and then left, to his maximum bending posture and then straightened slightly ( $5^{\circ}$ at most). In this posture he pulled upright as hard as he could on an anchored load cell.

A minimum of 1 minute's rest was given to the subject between each task, and no fatigue was reported by the subject during any of the tasks.

During the performance of all tasks, configurations and myoelectric measurements were made. The configuration measurements were made by locating a set of targets placed on the subject's right and left elbows, forehead, sternum and umbilicus.

A horizontal scale and plumb bob line were used to estimate, within 1 centimetre, the location of these targets in each configuration. Care was taken to ensure that no anterior/posterior flexion of the trunk occurred during lateral bending.

Myoelectric activity was measured by surface electrodes at eight sites. The axis of the bipolar electrodes was aligned parallel to the direction of the muscle fibres. All electrodes were placed at the $\mathrm{L}_{3}$ level. Approximate bilateral symmetry was assumed, so five of the electrodes were placed on the right side muscles and three placed over the left side muscles. Those three enabled the symmetry assumption to be checked. On the right side an electrode was placed on the hack $3 \mathrm{~cm}$ lateral to the midline of the spine at the $\mathrm{L}_{3}$ level. Another electrode was placed $6 \mathrm{~cm}$ lateral to the midline at the $\mathrm{L}_{3}$ level. Anteriorly, an electrode was placed over the right rectus abdominus muscle at the level of the umbilicus and $3 \mathrm{~cm}$ lateral to the midline. Another pair was placed over the right medial oblique abdominal muscles, $3 \mathrm{~cm}$ medially and superior to the anterior spine of the iliac crest, and another over the most lateral fibres of the right lateral oblique abdominal muscles.

On the left side an electrode was placed on the back, $6 \mathrm{~cm}$ lateral to the midline at the $\mathrm{L}_{3}$ level. Anteriorly, an electrode was placed over the left medial oblique abdominal muscles, $3 \mathrm{~cm}$ medial and superior to the anterior superior iliac spine, and another over the leftmost fibres of the lateral oblique abdominal muscles. A ground electrode was placed on the subject's right wrist.

The electrodes were filled with a conducting gel and attached to the subject's skin. The electrode signals were fed to pre-amplifiers, amplified again in main amplifiers, full wave rectified, integrated with a time constant of 0.2 $s$ and recorded on a chart recorder (Grass Instrument Co., Model 7P3 equipment) together with the load cell output. A visual examination was made on the myoelectric signals and any artifacts due to unwanted movements or coughs were eliminated. Root mean square 
(RMS) values over the recording period were estimated for each subject and each electrode. Finally, the mean and standard deviation of the RMS values were calculated over the nine subjects for each of the 22 tasks.

\section{Prediction of trunk muscle forces}

The contraction forces in the lumbar trunk muscles needed to perform each task along with the compression and shear load acting on the spine at the $\mathrm{L}_{3}$ level were calculated for each subject and for each individual task using the 22 muscle biomechanical model described by Schultz et al. ${ }^{5}$ This analysis began by computing first the net forces and moments needed to equilibrate the trunk at the $\mathrm{L}_{3}$ transverse section in the laterally-bent positions. The calculation of these net reaction components were made based upon the applied loads and the locations of the mass centres of the body segments. The weights of the head, each arm and the trunk above $\mathrm{L}_{3}$ were taken to be $5,4 \cdot 5$ and $36 \cdot 1 \%$ of the subject 's body weight, respectively. Then the contraction forces in the 22 model muscles along with the spine compression and shear loads were calculated by optimization techniques (Bean et al. ${ }^{1+}$ ). The objectives of this optimization were to minimize first muscle contraction intensity and then spine compression force. This technique maintains activity in antagonistic muscles at a minimum.

Essentially, this model computed a set of forces that would maintain equilibrium, with no distinction made between forces passively developed by the ligamentous tissues and forces actively developed by the muscles. It was assumed that the $L_{3}$ spine motion segment developed no significant moment resistance, but resisted compression, and lateral and antero-posterior shears. Furthermore, the effects of any abdominal cavity pressurization developed were neglected. The $L_{3}$ crosssectional geometry of the muscles modelled was estimated from anatomical drawings to be in proportion to the trunk depth and width at the $L_{3}$ level for each subject. Further details of this technique can be found in the earlier report of Schultz et al. ${ }^{3}$

The mean predicted muscle contraction tissue-tension forces were correlated with corresponding mean measured amplitudes of the myoelectric signals by a linear least squares regression analysis.

\section{Results}

The means of the largest observed myoelectric signals in the left and right lateral oblique abdominal muscles with a $0.0 \mathrm{~kg}$ applied load were 21.7 and $23.6 \mu \mathrm{V}$, respectively; and for a $5.0 \mathrm{~kg}$ applied load, 26.3 and $24.8 \mu \mathrm{V}$, respectively. Similarly, for the left and right erector spinae muscles $6 \mathrm{~cm}$ from the midline, the largest signals with $0.0 \mathrm{~kg}$ load applied were 23.5 and $27.3 \mu \mathrm{V}$ respectively, and for a $5 \cdot 0 \mathrm{~kg}$ load applied, $30 \cdot 2$ and $26 \cdot 3 \mu \mathrm{V}$. respectively (Tables $1 \& 2$ ).
The means of the corresponding largest predicted tissue tensions were $57 \cdot 3,59 \cdot 3,77 \cdot 1,68 \cdot 1,241 \cdot 0,249 \cdot 6$, 324.3 and $294.4 \mathrm{~N}$. The largest mean predicted compression on the $\mathrm{L}_{3}$ intervertebral disc was $1731 \mathrm{~N}$. The mean maximum lateral bending moment that the trunk structures resisted in these tasks was $56.1 \mathrm{Nm}$.

\section{Relaxation phenomena}

Relaxation phenomena would be characterized by the diminishing of the myoelectric signal levels despite increases in soft tissue tensions predicted to be required to equilibrate the trunk in laterally-bent positions. In this study, the oblique abdominal muscles showed no noticeable relaxation.
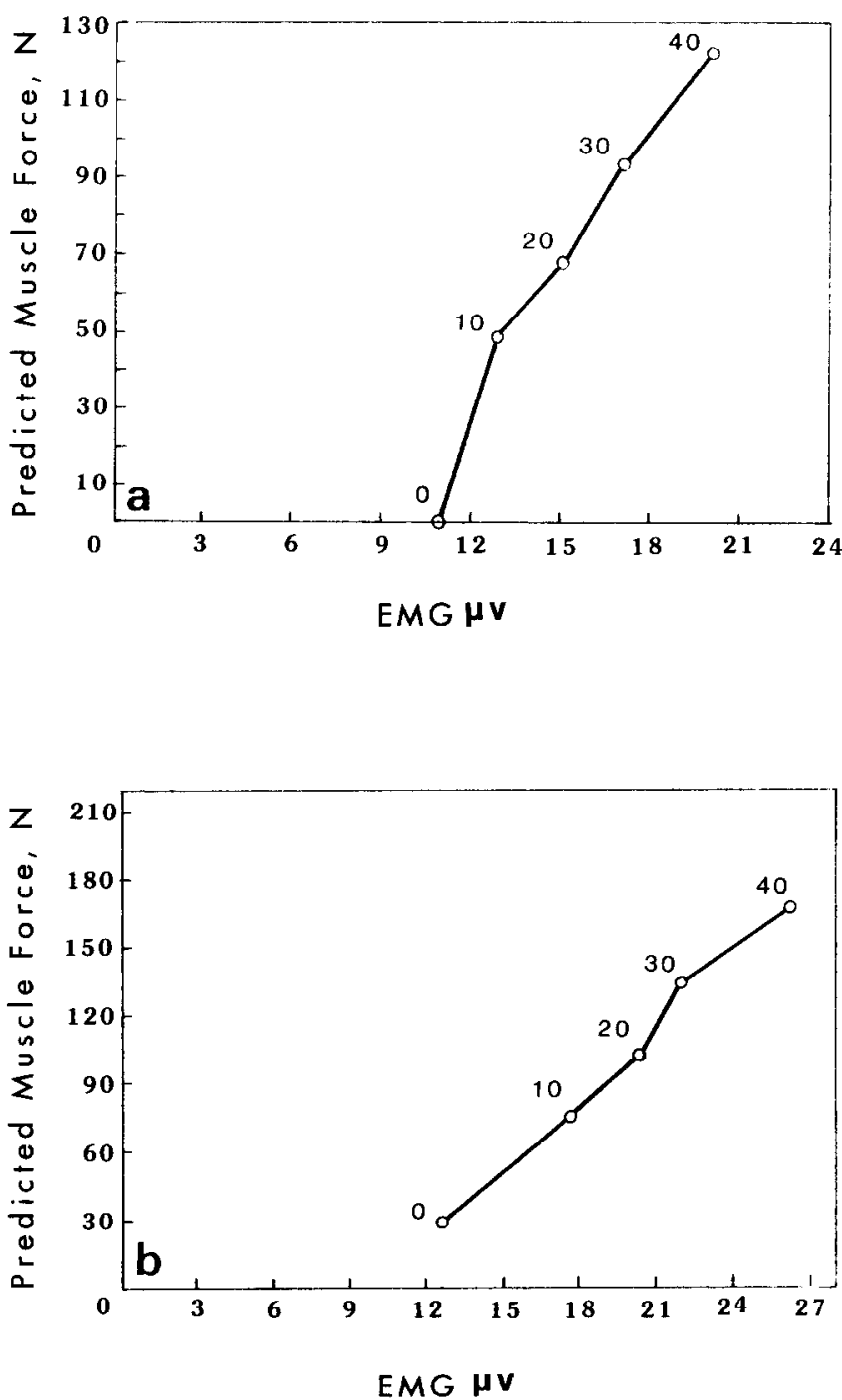

Figure 2: Mean measured $\mathrm{L}_{3}$ level myoelectric activity versus mean predicted tissue tension in the left lateral oblique muscles during quiet standing with 0.0 load at different angles (degrees) of right-lateral bending from upright position to maximum bending, a; results for the right muscles, b, during left-lateral bending with $5.0 \mathrm{~kg}$ load were similar. 
Table 1. Mean myoelectric signal amplitudes $(\mu \mathrm{V})$

Raftopoulos et al.: Relaxation phenomena in lumbar trunk muscles 169

\begin{tabular}{|c|c|c|c|c|c|c|c|c|c|c|}
\hline & & 0 & 10 & & 20 & & 30 & & 40 & 50 \\
\hline & & & $\begin{array}{l}0.0 \mathrm{~kg} \text { load } \\
\text { Erector spinae }\end{array}$ & & & & & & & \\
\hline \multicolumn{11}{|l|}{ Right bend: } \\
\hline From upright to maximum bend & 14.99 & $(0.58)$ & $15.68(0.58)$ & $16 \cdot 17$ & $(0.60)$ & $17 \cdot 07$ & $(0.60)$ & $17 \cdot 51$ & $(0.54)$ & \\
\hline \multicolumn{11}{|l|}{ Left bend: } \\
\hline $\begin{array}{l}\text { From upright to maximum bend } \\
\text { From max. bend to upright position }\end{array}$ & $\begin{array}{l}12 \cdot 00 \\
22 \cdot 62\end{array}$ & $\begin{array}{l}(0.82) \\
(1.16)\end{array}$ & $\begin{array}{l}15.08(0.73) \\
27.28(1.78)\end{array}$ & $\begin{array}{l}15 \cdot 33 \\
26 \cdot 65\end{array}$ & $\begin{array}{l}(0.61) \\
(1.48)\end{array}$ & $\begin{array}{l}18 \cdot 21 \\
25 \cdot 28\end{array}$ & $\begin{array}{l}(0.73) \\
(1.37)\end{array}$ & $\begin{array}{l}20 \cdot 22 \\
19 \cdot 18\end{array}$ & $\begin{array}{l}(1 \cdot 15) \\
(1 \cdot 19)\end{array}$ & $\begin{array}{l}21.69(1.21) \\
10.58(0.20)\end{array}$ \\
\hline & & & Lateral oblique & & & & & & & \\
\hline \multicolumn{11}{|l|}{ Right bend: } \\
\hline From upright to maximum bend & $10 \cdot 96$ & $(0.09)$ & $12.80(0.18)$ & 14.97 & $(0.38)$ & $17 \cdot 16$ & $(0.46)$ & $20 \cdot 84$ & $(0.87)$ & \\
\hline \multicolumn{11}{|l|}{ Left bend: } \\
\hline From upright to maximum bend & $11 \cdot 37$ & $(0.44)$ & $13.25(0.46)$ & $16 \cdot 77$ & $(0.51)$ & $18 \cdot 38$ & $(0.62)$ & $21 \cdot 23$ & $(1 \cdot 14)$ & $21.64(1.18)$ \\
\hline \multirow[t]{2}{*}{ From max. bend to upright position } & $23 \cdot 50$ & $(0.44)$ & $23.59(1.04)$ & $21 \cdot 30$ & $(0.82)$ & 18.44 & $(0.64)$ & $14 \cdot 15$ & $(0.34)$ & $11.15(0.10)$ \\
\hline & & & $\begin{array}{l}5.0 \mathrm{~kg} \text { load } \\
\text { Erector spinae }\end{array}$ & & & & & & & \\
\hline \multicolumn{11}{|l|}{ Right bend: } \\
\hline $\begin{array}{l}\text { From upright to maximum bend } \\
\text { From max. bend to upright position }\end{array}$ & $\begin{array}{l}18 \cdot 44 \\
26 \cdot 89\end{array}$ & $\begin{array}{l}(0 \cdot 75) \\
(1 \cdot 39)\end{array}$ & $\begin{array}{l}20.75(1.00) \\
30.09(1.82)\end{array}$ & $\begin{array}{l}21 \cdot 85 \\
30 \cdot 20\end{array}$ & $\begin{array}{l}(1.06) \\
(1.83)\end{array}$ & $\begin{array}{l}22 \cdot 79 \\
29 \cdot 21\end{array}$ & $\begin{array}{l}(0.82) \\
(1.78)\end{array}$ & $\begin{array}{l}28 \cdot 61 \\
23.93\end{array}$ & $\begin{array}{l}(1 \cdot 16) \\
(1 \cdot 58)\end{array}$ & \\
\hline \multicolumn{11}{|c|}{ 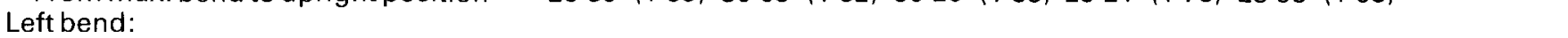 } \\
\hline From upright to maximum bend & $16 \cdot 14$ & $(0 \cdot 81)$ & $17.68(0.83)$ & $19 \cdot 01$ & $(0.77)$ & $22 \cdot 75$ & $(1 \cdot 27)$ & $25 \cdot 16$ & $(1.53)$ & \\
\hline \multirow[t]{2}{*}{ From max. bend to upright position } & $25 \cdot 61$ & $(1.51)$ & $26.29(1.77)$ & $25 \cdot 18$ & $(1.50)$ & $27 \cdot 21$ & $(1.50)$ & $16 \cdot 96$ & $(0.65)$ & \\
\hline & & & Lateral oblique & & & & & & & \\
\hline \multicolumn{11}{|l|}{ Right bend: } \\
\hline From upright to maximum bend & $12 \cdot 17$ & $(0 \cdot 16)$ & $17.71(0.54)$ & $20 \cdot 53$ & $(0.67)$ & $22 \cdot 10$ & $(0.76)$ & $26 \cdot 29$ & $(1.01)$ & \\
\hline From max. bend to upright position & $24 \cdot 80$ & $(1.01)$ & $22.09(0.72)$ & $20 \cdot 31$ & $(0.63)$ & $17 \cdot 45$ & $(0.55)$ & 13.03 & $(0.24)$ & \\
\hline \multicolumn{11}{|c|}{ 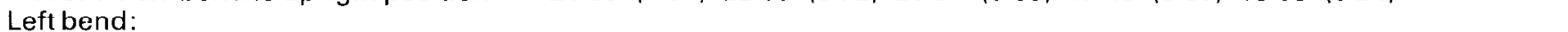 } \\
\hline From upright to maximum bend & $14 \cdot 70$ & $(0 \cdot 39)$ & $17 \cdot 20(0.39)$ & $20 \cdot 24$ & $(0.55)$ & $22 \cdot 89$ & $(0.93)$ & $22 \cdot 84$ & $(1.00)$ & \\
\hline From max. bend to upright position & $24 \cdot 85$ & $(1 \cdot 14)$ & $23.68(1.15)$ & $21 \cdot 20$ & $(0.94)$ & 18.02 & $(0.73)$ & $14 \cdot 31$ & $(0 \cdot 41)$ & \\
\hline
\end{tabular}

Table 2. Mean predicted forces (22 muscle model) $(N)$

\begin{tabular}{|c|c|c|c|c|c|c|}
\hline & 0 & 10 & 20 & 30 & 40 & 50 \\
\hline & & $\begin{array}{l}0.0 \mathrm{~kg} \text { load } \\
\text { rector spinat }\end{array}$ & & & & \\
\hline \multicolumn{7}{|l|}{ Right bend: } \\
\hline From upright to maximum bend & $1.9(0.2)$ & $71.7(3.2)$ & $137 \cdot 1(3 \cdot 7)$ & $189.8(3.7)$ & $241.0(3.0)$ & \\
\hline $\begin{array}{l}\text { From max. bend to upright position } \\
\text { Left bend: }\end{array}$ & $213 \cdot 0(3 \cdot 1)$ & $158 \cdot 3(3 \cdot 6)$ & $108 \cdot 3(5 \cdot 2)$ & $39.9(2.8)$ & $6.3(0.6)$ & \\
\hline From upright to maximum bend & $0.0(0.0)$ & $74.4(3.4)$ & $116 \cdot 2(3 \cdot 0)$ & $179.8(2 \cdot 8)$ & $218.3(3.4)$ & $245 \cdot 3(5 \cdot 2)$ \\
\hline From max. bend to upright position & $249 \cdot 6(5 \cdot 4)$ & $205 \cdot 6(6 \cdot 6)$ & $130 \cdot 2(4 \cdot 4)$ & $104 \cdot 3(4 \cdot 8)$ & $34.7(2.4)$ & $1.3(0.4)$ \\
\hline \multicolumn{7}{|c|}{ Lateral oblique } \\
\hline \multicolumn{7}{|l|}{ Right bend: } \\
\hline From upright to maximum bend & $0.5(0.1)$ & $17 \cdot 0(0 \cdot 8)$ & $32.6(0.9)$ & $45 \cdot 2(0.9)$ & $57.3(0.7)$ & \\
\hline From max. bend to upright position & $50.7(0.7)$ & $37.6(0.9)$ & $258.8(1.2)$ & $9.5(0.7)$ & $1.5(0.1)$ & \\
\hline \multicolumn{7}{|l|}{ Left bend: } \\
\hline From upright to maximum bend & $0.0(0.0)$ & $17 \cdot 7(0.8)$ & $27.6(0.7)$ & $42 \cdot 7(0.7)$ & $51.9(0.8)$ & $58 \cdot 3(1.2)$ \\
\hline \multirow[t]{2}{*}{ From max. bend to upright position } & $59 \cdot 3(1 \cdot 3)$ & $48.9(1.6)$ & $31 \cdot 0(1.0)$ & $24 \cdot 3(1 \cdot 0)$ & $8 \cdot 3(0 \cdot 7)$ & $0.3(0.1)$ \\
\hline & \multicolumn{3}{|c|}{$\begin{array}{l}5.0 \mathrm{~kg} \text { load } \\
\text { Erector spinae }\end{array}$} & & & \\
\hline \multicolumn{7}{|l|}{ Right bend: } \\
\hline From upright to maximum bend & $62.8(1.5)$ & $149 \cdot 1(2 \cdot 1)$ & $201.8(2.8)$ & $258.4(3.6)$ & $324 \cdot 3(4 \cdot 6)$ & \\
\hline From max. bend to upright position & $273.1(3.8)$ & $232.0(3.7)$ & $179 \cdot 6(4 \cdot 3)$ & $129.5(7.0)$ & $45.7(3.0)$ & \\
\hline \multirow{4}{*}{$\begin{array}{l}\text { From upright to maximum bend } \\
\text { From max. bend to upright position }\end{array}$} & & & & & & \\
\hline & $54.5(1.8)$ & $116 \cdot 6(2 \cdot 3)$ & $194 \cdot 1 \quad(6 \cdot 1)$ & $246 \cdot 8(4 \cdot 7)$ & $294.4(3.6)$ & \\
\hline & $281 \cdot 8(3 \cdot 1)$ & $227 \cdot 2(8.2)$ & $176 \cdot 2(6 \cdot 5)$ & $99 \cdot 0(4 \cdot 0)$ & $47 \cdot 2(1 \cdot 1)$ & \\
\hline & \multicolumn{3}{|c|}{ Lateral oblique } & & & \\
\hline \multicolumn{7}{|l|}{ Right bend: } \\
\hline From upright to maximum bend & $14.9(0.4)$ & $22.5(0.5)$ & $48 \cdot 0(0.7)$ & $61.5(4 \cdot 8)$ & $77 \cdot 1(1 \cdot 1)$ & \\
\hline From max. bend to upright position & $64.9(0.9)$ & $55.2(0.9)$ & $42.7(1.0)$ & $30 \cdot 8(1 \cdot 7)$ & $10.9(0.7)$ & \\
\hline \multicolumn{7}{|l|}{ Left bend: } \\
\hline From upright to maximum bend & $13.0(0.4)$ & $27.7(0.5)$ & $44.2(1.4)$ & $57.5(1.1)$ & $68.1(0.7)$ & \\
\hline From max. bend to upright position & $67.0(0.7)$ & $54.0(1.9)$ & $41.9(1.5)$ & $23.6(0.9)$ & $11 \cdot 1 \quad(0.3)$ & \\
\hline
\end{tabular}




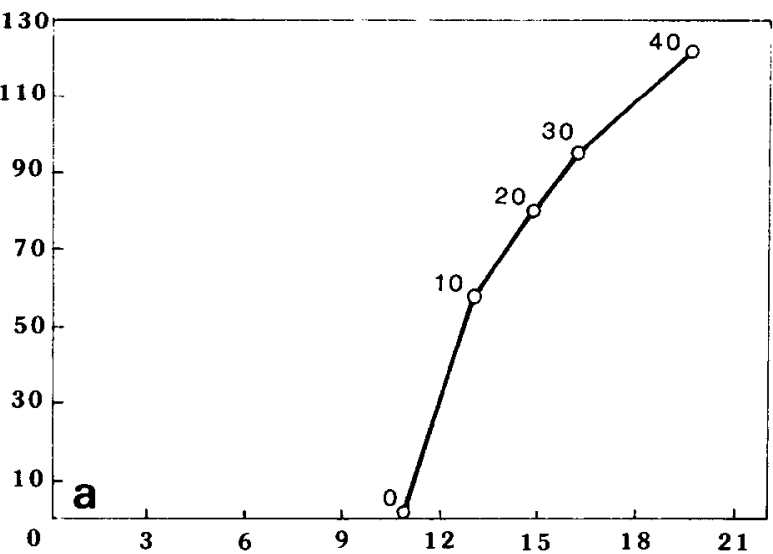

EMG $\boldsymbol{\mu v}$

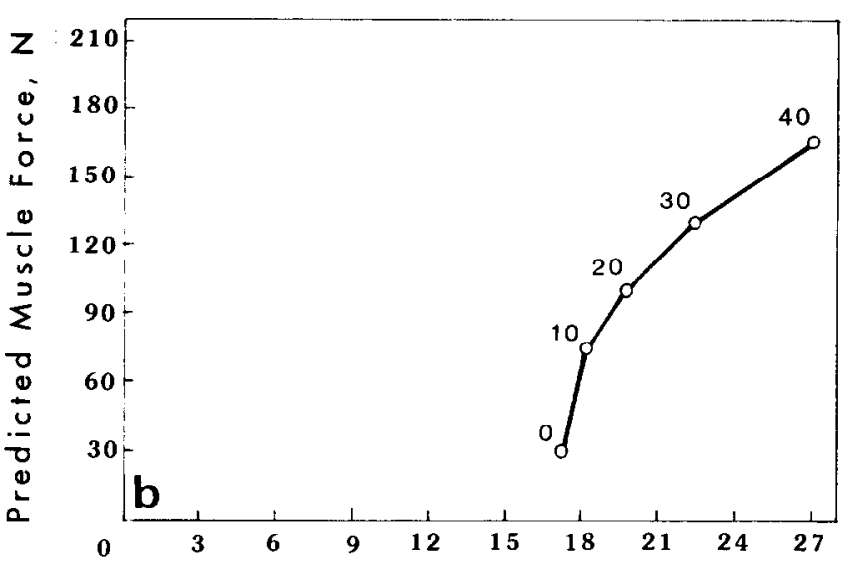

EMG $\mu v$

Figure 3: Mean measured $L_{3}$ level myoelectric activity versus mean predicted tissue tension in the left medial oblique muscles during quiet standing with, $\mathbf{a}, 0.0$ and, $\mathbf{b}, 5.0 \mathrm{~kg}$ load at different angles of right-lateral bending from upright position to maximum bending. Results for the right muscle during left-lateral bending were similar.
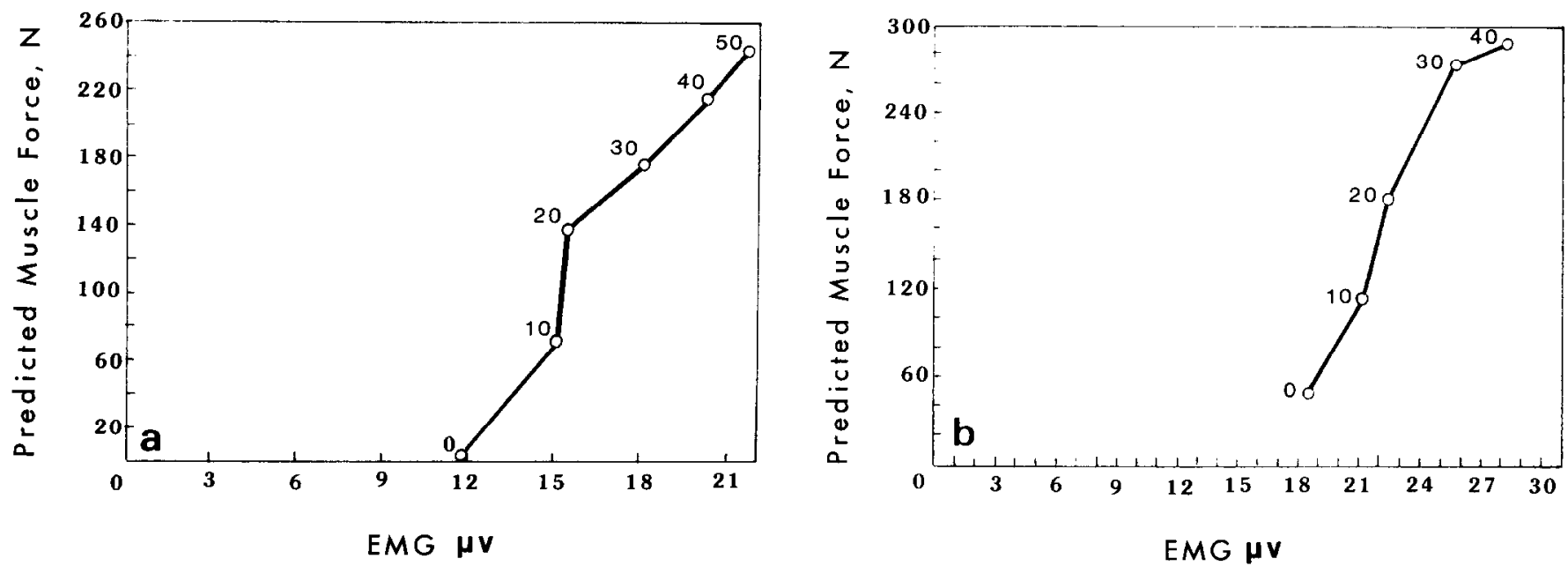

Figure 4: Mean measured $\mathrm{L}_{3}$ level myoelectric activity versus mean predicted tissue tension in the left erector muscles, located $6 \mathrm{~cm}$ lateral of the spine, during quiet standing with, a, 0.0 and, b, $5.0 \mathrm{~kg}$ load at different angles of right-lateral bending from upright position to maximum bending. Results for the right muscle during left-lateral bending were similar. 


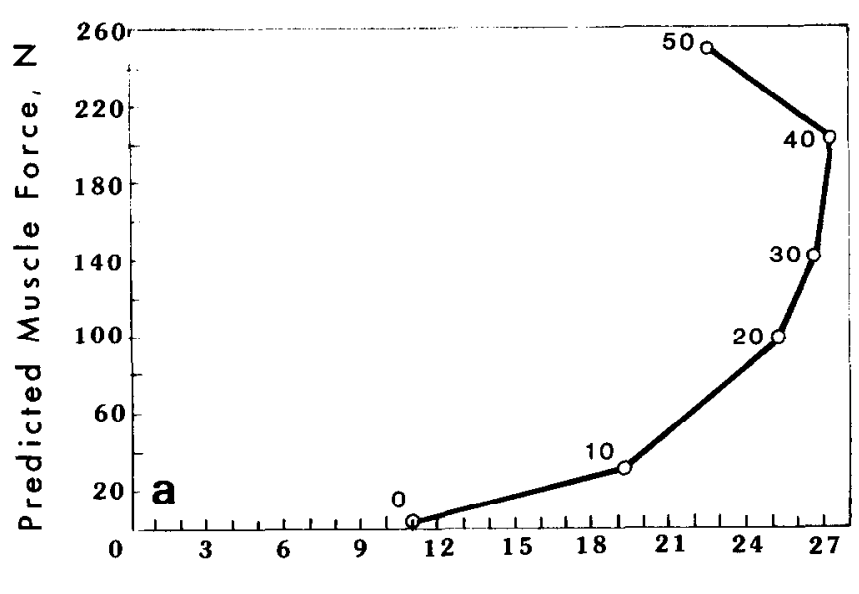

EMG $\boldsymbol{\mu v}$

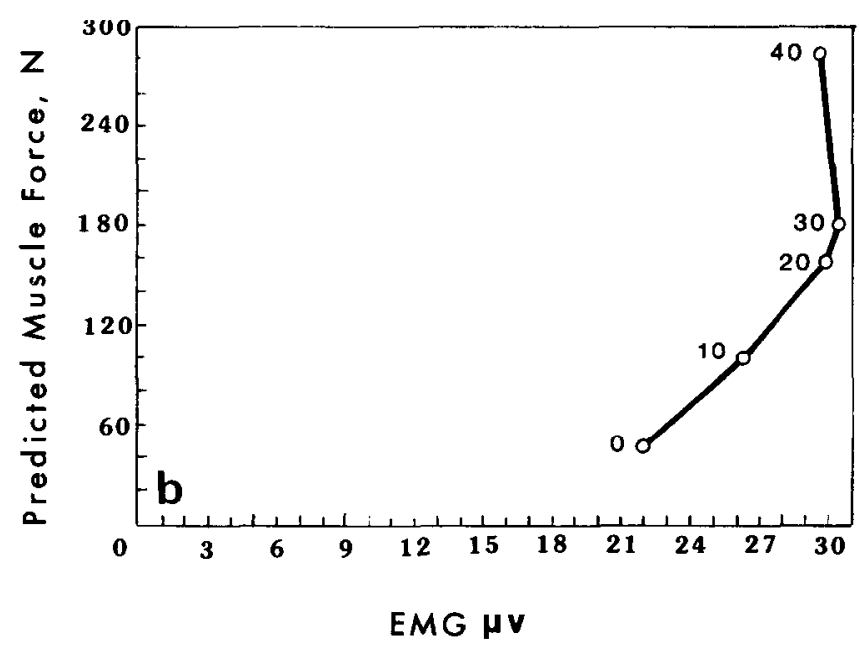

Figure 5: Mean measured $L_{3}$ level myoelectric activity versus mean predicted tissue tension in the right erector muscles, located $6 \mathrm{~cm}$ lateral of the spine, during quiet standing with, a, 0.0 and, b, $5.0 \mathrm{~kg}$ load at different angles of left-lateral bending from maximum bending to upright position. Results for the left muscle during right-lateral bending were similar.

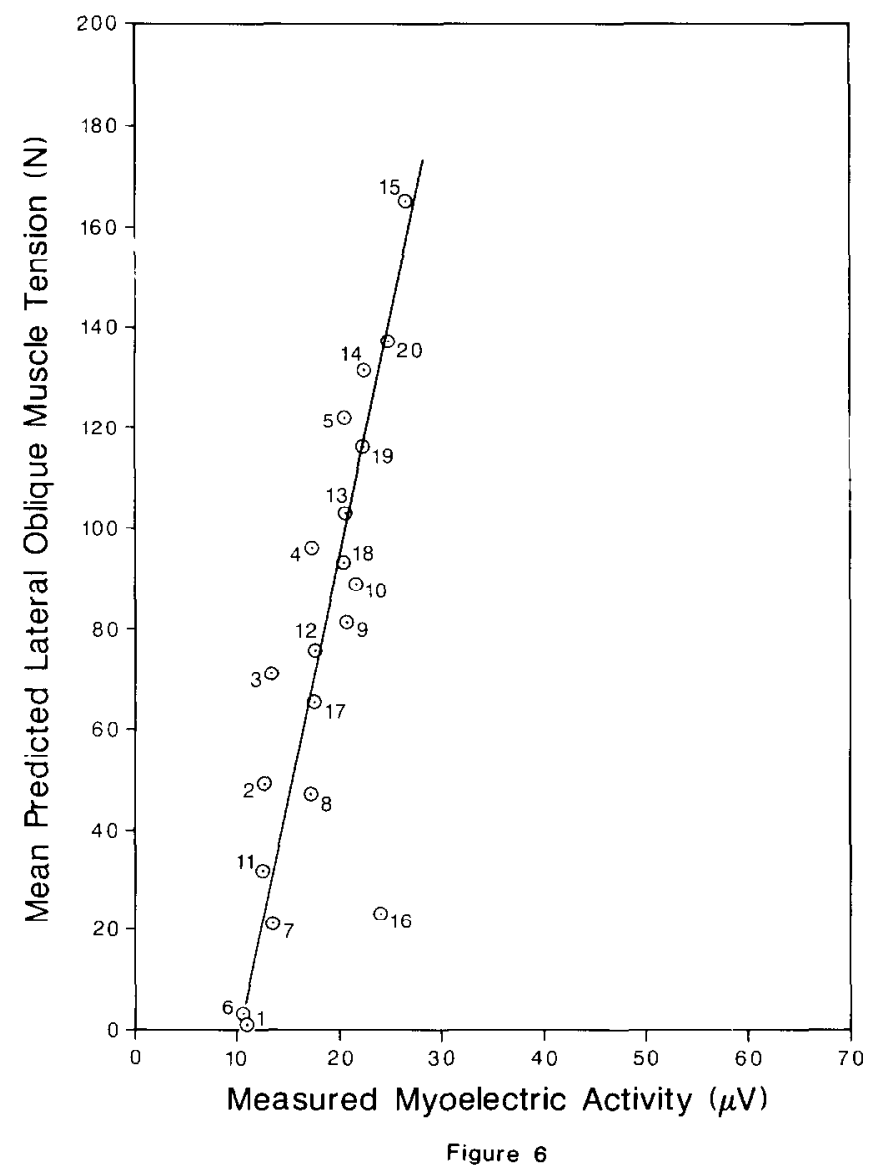

Figure 6: Predicted contraction forces versus measured myoelectric activities in left-lateral oblique muscles. Each point shows nine subject mean values of forces and of electrical activities for one task, for a total of 20 tasks.

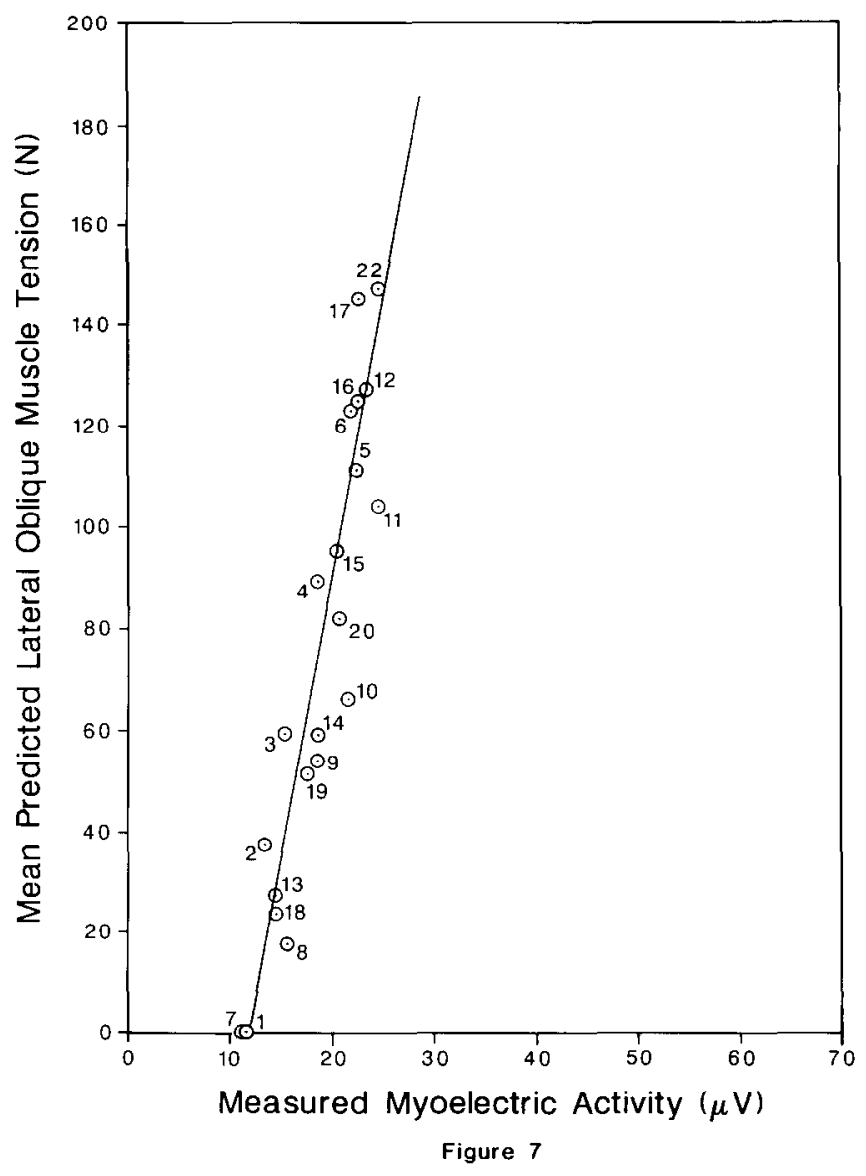

Figure 7: Predicted contraction forces versus measured myoelectric activities in right-lateral oblique muscles. Each point shows nine subject mean values of forces and of electrical activities for one task, for a total of 20 tasks. 
The mean measured myoelectric activity in the oblique abdominal muscles was plotted against the mean predicted tissue tension for those tasks involving quiet standing in laterally bent positions, both when the subject was not (Figures 2a,b) and when he was (Figures $3 a, b)$ holding a $5 \mathrm{~kg}$ mass in his hand on the side to which bending had occurred. It can be observed from these two figures that no lateral-bending relaxation was detectable in the left oblique abdominal muscles. Similar results were obtained for the right side oblique muscles.

Relaxation did occur in the erector spinae muscles. When similar plots were constructed for the erector spinac muscles these muscles did not demonstrate relaxation during lateral bending from upright to maximum bending positions (Figures $4 a, b$ ). However, these muscles exhibited relaxation during straightening from maximum bending to upright positions (Figures $5 \mathrm{a}, \mathrm{b}$ ).

\section{Linearity of the myoelectric signal predicted tension relations}

Plots of nine-subject-mean predicted contraction forces versus measured myoelectric activities in the left and right lateral oblique muscles for the tasks performed showed (Figures 6 and 7) the same high degree of linear correlation exhibited in the studies of trunk biomechanics cited earlicr. The coefficients of linear correlation for these relations were between 0.72 and 0.87 on both the left and right sides. This suggests that the muscle contraction force predictions were reasonably valid when relaxation phenomena were not present.

\section{Discussion}

It appears that when standing in a maximum laterally bent position, passive mechanisms for the maintenance of equilibrium are present, although their effects are not strong ones. These effects are no longer seen once 30 $40^{\circ}$ of lateral bending are reached upon the return from the maximum position. Furthermore, these mechanisms are present only in the erector spinae muscles, the same muscles that exhibit flexion-relaxation ${ }^{5}$.

\section{Conclusions}

1. The lumbar trunk structures resisted up to $1731 \mathrm{~N}$ in compression and up to $56.1 \mathrm{Nm}$ in lateral bending moment in the lateral bending tasks studied.

2. The levels of surface myoelectric activity found in lumbar trunk muscles in quiet standing with various degrees of trunk lateral bending were as high as 27.3 $\mu \mathrm{V}$ for a $0.0 \mathrm{~kg}$ load and $30.2 \mu \mathrm{V}$ for a $5.0 \mathrm{~kg}$ load applied.

3. In the oblique abdominal muscles, no muscle relaxa- tion was observed to occur in quiet standing in laterally-bent positions of the trunk. In the erector spinae muscles, however, a relaxation phenomenon qualitatively similar to the flexion-relaxation phenomenon was observed.

4. Trunk muscle myoelectric activities increased when external forces were applied to the trunk in bent configurations.

\section{Acknowledgements}

This work was performed at the Biomechanics Laboratory, Department of Mechanical Enginecring and Applied Mechanics, the University of Michigan, Ann Arbor, Michigan. DD Raftopoulos was Visiting Professor at the Department of Mechanical Engineering and Applicd Mechanics, The University of Michigan, Ann Arbor, Michigan from August 1985 to August 1986. The support of Public Health Service Grants OH10962 and NS20536 for this research is gratefully acknowledged.

\section{References}

I Andersson GBJ, Ortengren R, Schultz AB. Analysis and measurement of the loads on the lumbar spine during work at a table. J Biomech 1979; 13: 513-20

2 Schultz AB, Andersson GBJ. Analysis of loads on the lumbar spine. Spine 1981; 6: 76-82

3 Schultz A, Andersson GBJ, Ortengren R. Bjork R, Nordin $M$. Analysis and quantitative myoelectric mcasurements of loads on the lumbar spine when holding weights in standing postures. Spine 1982: 7: 390)-7

4 Schultz A, Andersson G, Ortengren R, Haderspeck K, Nachemson A. Loads on the lumbar spine. J Bone Jt Surg 1982; 64: 713-20

5 Schultz A. Haderspeck K. Warwick D, Portillo D. Use of lumbar trunk muscles in isometric performance of mechanically complex standing tasks. J Orthop Res 1983: 1: 77-91

6 Fick R. Handbuch der Anatomie und Merchanik der Gelenke, Vol. 3. Jena: Gustav Fischer. 1911

7 Allen C. Muscle action potentials used in the study of dynamic anatory. Br J Phys Med 1948; 11: 66

8 Floyd WF, Silver PHS. Function of the erectores spinae in flexion of the trunk. Lancet 1951: 2: 133-4

9 Floyd WF, Silver PHS. The function of the erectores spinac muscle in certain movements and postures in man. J Physiol (Lond) 1955: 129: 184-203

10 Portnoy H, Morris F. Electromyographic study of the postural muscles in various positions and movements. Am J Physiol 1956; 186: 122-6

11 Pauly JE. An electromyographic analysis of certain movements and exercises. Anat Rec 1966; 155: 233-4

12 Kippers V, Parker AW. Posture related to myoelectric silence of erectores spinae during trunk flexion. Spine 1984; 9: 740-5

13 Schultz A. Haderspeck K, Sinkora G. Warwick D. Quantitative studies of the flexion-relaxation phenomenon in the back muscles. J Orthop Res 1985; 3: 189-97

14 Bean JC, Chaffin DB, Schultz AB. Biomechanical model calculation of muscle contraction forces: a double linear programming method. J Biomech 1988; $21: 59-66$ 